\title{
Adolescence, Internet Use, Social Adjustment and Emotional Intelligence
}

\author{
Dr. Petro van der Merwe \\ University of South Africa \\ Email:vdmerp1@unisa.ac.za
}

Doi:10.5901/mjss.2014.v5n23p2327

\begin{abstract}
Instead of merely focusing on the use of new media itself, attention should also be given to the users in terms of their ability to interact with other people. The effect of the internet could be an increased variance in social adjustment rather than an average improvement or deterioration. Adolescent internet users might be well adjusted, as they report higher levels of social activity and network involvement; however, internet use and social involvement tend to vary according to education, income and age. Therefore other variables need to be investigated in order to determine the extent to which social isolation and behaviour problems are a result of internet use, regardless of any inherently social disposition on the part of the user. It is not the aim of this article to investigate whether socially isolated adolescents were deficient in social skills even before taking up the internet. The purpose is to investigate the extent to which emotional and interpersonal skills are related to internet use. The main relevant argument is that the internet will cut adolescent users off from genuine social relationships and ultimately lead to impoverished participation in social life. Counter-arguments highlight the potential of new media to enhance adolescents' social lives as it enables them to engage more easily in communication with their peer group. The importance of peers is one feature of adolescence. Adolescents spend a great deal of time with friends and place a high value on these relationships. In order to determine whether internet use does in fact have a negative impact on social adjustment, it is important to understand what emotions are, and what exactly constitutes emotional intelligence. When used responsibly, the internet can be a great place to interact socially. Consequently, this generation requires a unique brand of education that will enable them to realize their personal dreams and serve the society they are a part of.
\end{abstract}

Keywords: Adolescence; Internet use; emotional and interpersonal skills; Social relationships; Social adjustment; Emotional intelligence; Digital media literacy

\section{Introduction}

For much of the previous century, emotion scholars generally subscribed to a cultural theory of emotion: emotions were believed to be culturally specific learned behaviours that could only be experienced by observing other people expressing such emotions (Creed \& Beale, 2006). However, Ekman (1999:43) discovered that some emotions are not necessarily learned as previously believed, but are in fact innate and shared across cultures. In his study, the researcher classified anger, disgust, fear, joy, sadness and surprise as emotions that are shared across cultures, and called them 'basic emotions'.

Humans can express emotions in a variety of ways, the primary ones being the following (Creed \& Beale, 2006:123):

- Written language. People often express their emotions via stories, poetry and personal letters. People can literally state how they are feeling using emotive words such as 'happy', 'sad' or 'ecstatic' (Wang, Predinger, \& Igarashi, 2004:1172).

- Speech. People can use speech to simply communicate the emotions they are experiencing. Pitch (level, range and variability), tempo and loudness are considered the most influential parameters for expressing emotion through speech (Bartneck, 2001:279).

- Facial expression. Humans are particularly adept at recognising emotion in facial expression, and research has shown that people can accurately identify the emotional expression on faces by concentrating on the mouth, cheeks, eyes, eyebrows and forehead (Etcoff \& Magee, 1992:227).

- Gestures and body language. This can be explained in the meaning of different head, hand and body movements. For example, a vertical (up and down) nod of the head often displays agreement or comprehension while listening. Clenched fists can signal an aroused emotional state, such as fear, anger or excitement (Givens, 2002:38). 
One of the major disadvantages that computers have over humans is that they do not have the sensory organs of humans, such as eyes and ears, to recognise emotional responses (Gratch \& Marsella, 2005b). Recent progress has been made in building emotional voice recognition software and applications that can track subtle facial movements and measure physiological signals associated with emotion (Carberry \& De Rosis, 2008). However, much work is needed in developing a model that enables computers to express emotions believably at both the right intensity and the appropriate time; in other words, an emotional response similar to that of a human (Trappl, Petta, \& Payr, 2003).

The absence or the rich non-verbal cues that guide people well in face-to-face encounters are absent online; therefore the 'cold' nature of online communication can lead to problems (Mueller, 2000:1). Because of this lack of nonverbal cues, online activities strengthen a number of social psychological problems, such as the fundamental attribution error, where people interpret others' misbehaviour as representative, whereas their own mistakes have a good explanation, rendering them atypical: Your email has spelling errors because you are an ignorant, clumsy slob, whereas I was just distracted by the telephone (Mueller:1). Furthermore, many online activities are asynchronous; that is, my turn and now your turn, rather than simultaneous as in face-to-face situations (Birnbaum, 2000). As a result, online activities are vulnerable to a number of issues having to do with using stereotypes to provide some of the missing detail and structure in situations that approach anonymity (McKenna \& Bargh, 2000).

\section{Emotional Intelligence}

Emotional intelligence has long been a popular topic among behavioural psychologists in understanding how people identify, assess and control their emotions (Goleman, 1996, 2004; Mayer, Caruso, \& Salovey, 2000; Salovey \& Mayer, 1990). Segal (2008) maintains that emotional intelligence is the ability to recognise the emotions in yourself and those of others around you, manage for potential effects of your emotions on others, and consider all of the emotions in relations and in decision-making and problem-solving. Emotional intelligence is also about engaging with others in ways that draw people to you.

The concept of emotional intelligence therefore consists of four core abilities (Segal, 2008):

- self-awareness - accurately perceiving emotion;

- self-management - using emotions to facilitate thinking;

- social awareness - understanding emotional meanings, and

- relationship management - managing emotions to develop and maintain good relationships.

Pupils ability to memorise, solve problems, spell words and do mathematical calculations are easily measured by written tests and presented as grades on report cards. Eventually, these intellectual abilities dictate which university or college will accept pupils and which career paths they are advised to follow (Segal, 2008). However, intellectual intelligence is usually less important in determining how successful persons are than emotional intelligence (Goleman, 2004). We all know people who are academically brilliant and yet socially incompetent and unsuccessful. What they are lacking is emotional intelligence (Goleman, 2004).

Emotional intelligence consists of five key skills, each building on the last (Segal, 2008):

- Emotional intelligence skill 1: The ability to quickly reduce stress.

- Emotional intelligence skill 2: The ability to recognise and manage your emotions.

- Emotional intelligence skill 3: The ability to connect with others using non-verbal communication.

- Emotional intelligence skill 4: The ability to use humour and play to deal with challenges.

- Emotional intelligence skill 5: The ability to resolve conflict positively and with confidence.

These five skills can be learned by anyone at any time. However, emotional intelligence is not learned in the standard intellectual way - it must be learned and understood on an emotional level (Goleman, 2004). In order to learn about emotional intelligence in a way that produces change, adolescents need to engage the emotional parts of the brain in ways that connect them to others (Segal, 2008). This kind of learning is based on what individuals see, hear and feel. Intellectual understanding is an important first step, but the development of emotional intelligence depends on sensory, non-verbal learning and real-life practice (Segal, 2008).

Since the internet has become an ingrained part of adolescents' lives due to the proliferation of cellphones that synchronise with the internet, which has had the effect of adolescents chatting and sending messages on a nearly constant basis, the learning of emotional skills has become more of a problem. Bandwidth on handheld devices and the interfaces on them have increased to the point where adolescents can really fire messages back and forth (Bradberry \& Greaves, 2009). Adolescents are at the point where they are forgetting to actually communicate either verbally or in person. According to Bradberry and Greaves (2009), the biggest mistake people make in sending messages online is not 
considering how the recipient of the message will react when he or she reads it. These authors are of the opinion that the fact people tend to lose sight of very quickly is the perspective of the other person. People are so focused on what they need to say and how they are going to say it that they lose sight of how the message is going to be received. When talking to someone face to face it is much easier to put yourself in his or her shoes because you are actually watching them respond to what you are saying. This confirms the hypothesis of this study that internet use could be negatively related to interpersonal skills.

\subsection{Emotional skills on the internet}

The internet has a rather confused image in terms of emotions. On the one hand, as a complex technical system it is frequently portrayed as evacuating emotions and depersonalising relationships (Staples, 2004). Or, if there are emotions, they are seen to be doubtful, fake, false, and unreal, with notable stories of people playing at what they are not. As Lewis (2003) observed in his book Next: The Future Just Happened, adolescents see the internet as a transformational device that lets them discard quotidian identities for more glamorous ones. Lewis (2003) illustrated this point with a 15-year-old boy who adopted a pseudonym as a 25-year-old legal expert for an internet information service. The boy did not feel the least bit guilty, and was not deterred when real-world lawyers discovered his secret and accused him of being a fraud. When asked whether he had actually read the law, the boy responded that he found books boring, leaving us to conclude that he had learned all he needed to know from the internet.

Adolescents of today are a generation of the internet, where everyone has a pseudonym, where telling a story makes it true, and where adolescents can create older, cooler, more socially powerful selves any time they wish. This provides the opportunity for emotionally fragile adolescents to slip easily into a new, false, self-tailor-made identity (Staples, 2004). The internet is pictured as the land of extremes: sex, violence, racism and religious fanaticism (Gorman \& McLean, 2009). Emotions online can still be quite strong. 'Flaming' is a common phenomenon in which people lose themselves to become very angry online from the supposed security of their private space on the safe side of the screen (Orlik, Anderson, Day, \& Patrick, 2007). However, this lack of self-restraint is not limited to the online community; it is part of a more widespread move to unbridled individualism and the absence of consideration for others (Kirsh \& Becker, 2006).

It is through emotional intelligence that persons are able to figure out what is socially relevant and to interact appropriately based on how individuals in relationships feel about each other (Mayer et al, 2000). In order to determine whether emotional intelligence varies based on internet use, Engelberg and Sjöberg (2004) conducted a series of battery tests. Forty-one individuals, aged 18 to 21, were given these tests, which measured their level of loneliness, internet addiction, ability to identify emotions in social episodes, and a few other scales. The results of the study indicated that high- and low-frequency users of the internet differed in a number of ways from each other. Figures 1, 2, 3 and 4 illustrate how frequency of internet use is related to loneliness, emotional intelligence, deviant values and lack of life balance according to standardised values (Engelberg \& Sjöberg, 2004).

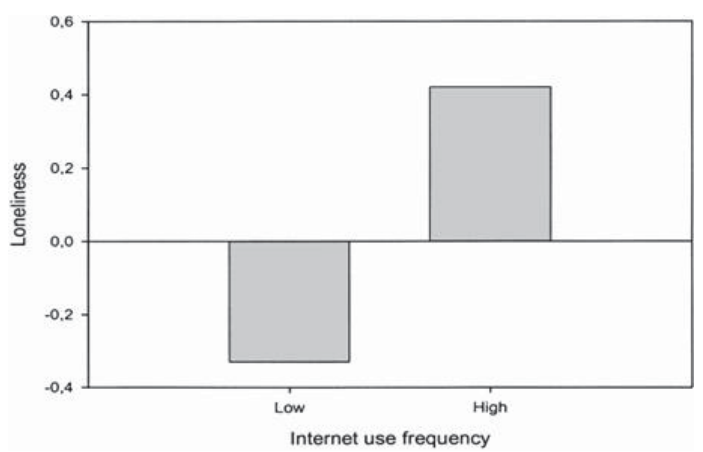

Figure 1: Means of loneliness for high- and low-frequency users of the internet (Engelberg \& Sjöberg, 2004, p. 44). 


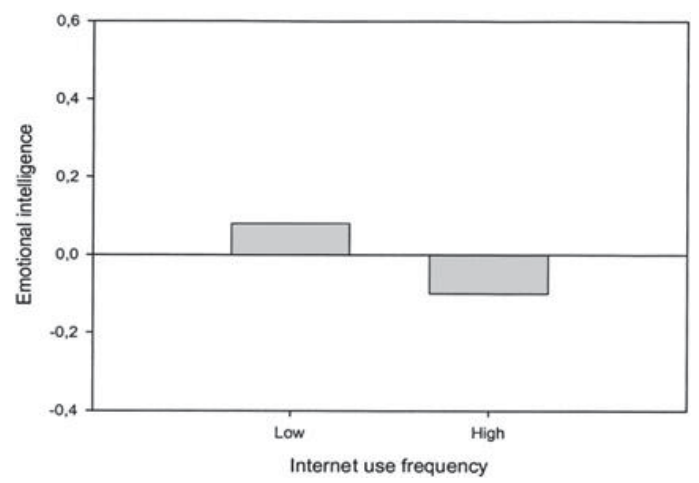

Figure 2: Means of emotional intelligence for high- and low-frequency users of the internet (Engelberg \& Sjöberg, 2004, p. 45).

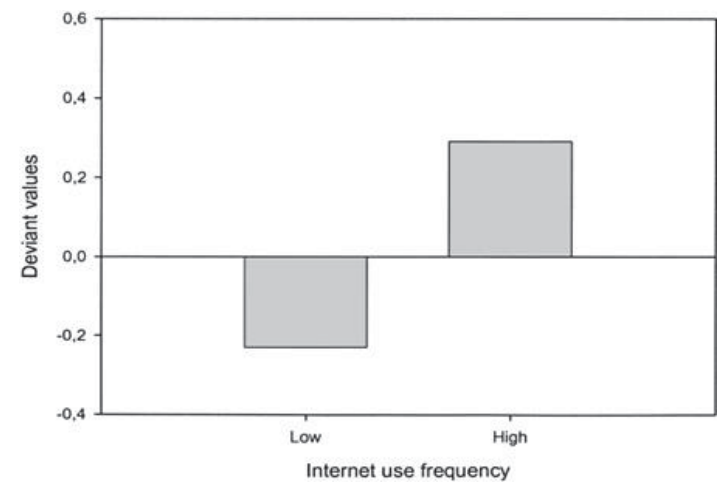

Figure 3: Means of deviant values for high- and low-frequency users of the internet (Engelberg \& Sjöberg, 2004, p. 44).

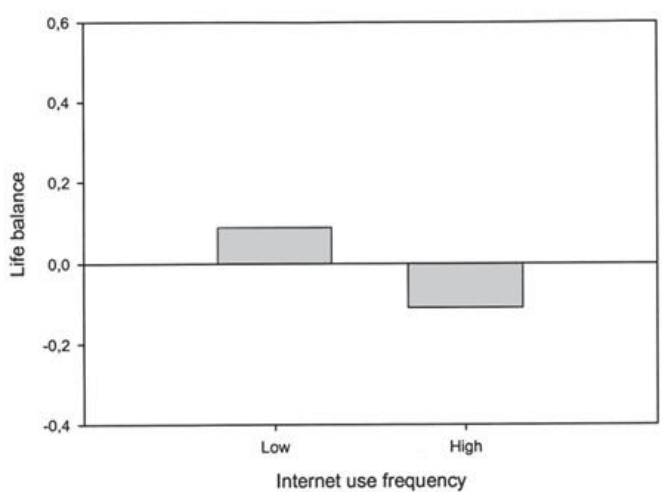

Figure 4: Means of life balance for high- and low-frequency users of the internet (Engelberg \& Sjöberg, 2004, p. 45).

The above figures confirm the expectation of this study that frequent users of the internet would be lower than others on emotional intelligence. These results therefore suggest that frequent users of the internet tend to lack the emotional competence characteristic of high emotional intelligence, which constitutes an advantage for social adaption. One reason this might be the case is that people with high emotional intelligence simply do not use the internet as much. This is because they prefer face-to-face interactions, owing to them being more sensitive to the emotions of others, and this kind of interaction is difficult to achieve on the internet.

Another interesting finding of the mentioned study was that high-frequency users of the internet subscribed to more deviant and idiosyncratic values and had less elaborate social networks, as indicated by their lower score on the balance 
scale, in addition to their tendency to report a greater sense of loneliness (Engelberg \& Sjöberg, 2004). The values measured in the study conducted by Engelberg and Sjöberg (2004), were on the dimensions of freedom and achievement, tradition and hierarchy, equality and justice, and stimulation, excitement. Having deviant values simply means that high-frequency users of the internet had scores on these dimensions that deviated from the mean. It may be that, because people have deviant values, they resort to spending time on the internet instead of having a social life in the real world (Singh, 2010). It could also be that frequent use of the internet results in exposure to and the eventual adoption of new value systems. According to Singh (2010), the relationship between internet use and having deviant values needs further research to determine the causal direction.

Psychological research has shown that personality variables are differentially associated with the tendency to seek company and get socially involved (Von Dras \& Siegler, 1997). For example, extroverts have been found to be gregarious, friendly and socially facile and to have more elaborated social networks (Von Dras \& Siegler). In the context of internet use it has been found that extroverts are less inclined to solicit social services offered on the internet, presumably because their need for social exchange is sufficiently met offline (Correa, Hinsley, \& De Zuniga, 2010; Hamburger \& Ben-Artzi, 2000). Agreeableness is another variable that reliably predicts aspects of social behaviour (Tobin, Graziano, Vanman, \& Tassinary, 2000). Agreeableness is related to interpersonal processes involved in promoting social relations.

Studies on the social consequences of the internet have suggested opposing hypotheses on how introverts and extroverts may use the internet (Gross, Juvonen, \& Gable, 2002; Kraut, Kiesler, Boneva, Cummings, Helgeson, \& Crawford, 2002). Kraut, Patterson, Lundmark, Kiesler, Mukhopadhyay and Scherlis (1998) reported negative effects of using the internet on measures of social involvement. These authors called the effects a 'paradox' because participants in the study used the internet heavily for communication, which generally has positive effects. In a three-year follow-up of the original study, Kraut et al (2002) found that the negative effects dissipated over the period. The results of the followup study showed overall positive effects of using the internet on communication, social involvement and well-being.

Using the internet generally predicted better outcomes for extroverts or those with more social support, and worse outcomes for introverts or those with less support. According to this rich-get-richer hypothesis of Kraut et al (2002), the internet will be used mainly by extrovert and outgoing adolescents, who will use the web to add more contacts to their already impressive reservoir of friends (Figure 5). Kraut et al (2002) stated that, although using the internet had slightly different benefits for adolescents and adults, controlling for age did not change the main conclusions.

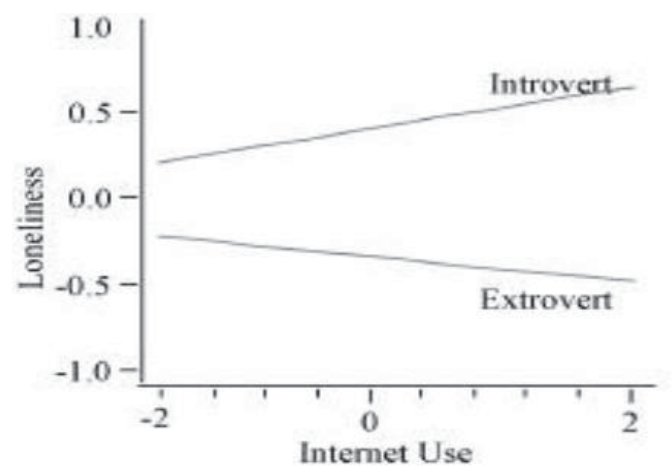

Figure 5: The effect of the interaction between internet use and extroversion on loneliness (Kraut et al. 2002, p. 61).

In contrast, McKenna and Bargh's (2000) social compensation hypothesis proposes that the internet will be used especially by introvert and socially anxious adolescents, who have difficulty developing friendships in their real-life environment.

A more constructive approach to emotions and the internet might be to raise the question of what emotional and relational skills are required in the online world and how these might be acquired or enhanced. Following are four suggestions:

\subsection{Attentive reading, thoughtful writing}

Almost all online exchange is text-based. As a result, emotional and relational skills have a great deal to do with picking up emotional signals in what others write and being aware of the emotional impact of what you yourself write (Gratch \& 
Marsella, 2005a). As text lacks many of the emotional clues that enrich face-to-face exchange, it is all the more important to pay particular attention to how words are used. That is, to consider what conviction, value judgements and emotions words express and how they are perceived by readers.

Writing, as it is taught in schools, has to do with grammatical and lexical correctness and the appropriateness of the structuring of ideas. The initial effort necessary with the emotional aspect of writing is one of awareness (Goleman, 2004). Ways and means have to be devised to draw adolescents' attention to this facet of online exchange. The colour, size and shape of words can also be manipulated to add emotional emphasis to content, for example by animating text (Wang et al, 2004). Symbols like :-) for happy or :-( for sad can also be used to convey emotion and are particularly popular in domains where emotional information is lacking, such as email, instant messaging and SMSing (Creed \& Beale, 2006).

\subsection{Dealing with your own emotions}

In communication carried out at a distance such as via email it is easy to misinterpret what is written and to attribute intentions that are not necessarily there. The online world requires one to make a clear distinction between one's own emotions and those one attributes to others and what they really think and feel (Jacko, 2007). Once again, awareness is the first step in becoming attentive to this aspect of communication (Goleman, 2004).

It helps to ask yourself what you are feeling and how these feelings are being expressed in what you write. Ideally, you also need to be able to ask for clarification when there is doubt (HayGroup, 2011). This can be difficult in a world where quick results are required and emotions are seen as extraneous. According to the HayGroup (2011), there is a need to create a considerate culture in which it is known that speed of delivery can result in loss of quality, especially when it leads to ignoring potential misunderstandings and conflict.

\subsection{Collaborative working}

Collaborating with others, especially online, requires a certain amount of self-restraint, as well as concern and respect for the others involved. Misplaced or ill-chosen words can do much damage (Carroll, 2003). In working online, there is a great need to understand and clarify the work that is being done together (HayGroup, 2011). In collaborative working, there is a great need to encourage all the members of the team. Recognising the value of the others in the group and letting them know you appreciate them can be quite a help. Compliments and praise are all too rare. You need to be open to what others are suggesting and to be able to capitalise on their ideas, however strange they may seem to you. At the same time you need to be able to assert your opinion without seeming aggressive or domineering (HayGroup, 2011).

Ideally, adolescents should be able to discuss these considerations with their online peer group. Such online exchange not only allows them to make the most of the experience of others, but will also help them to formulate their thoughts clearly in writing and realise the value of their own experience (Tarpley, 2001).

\subsection{Assisting learning}

Another area where emotions can be critical is that of learning. It has been argued that the ability to show emotions and empathy through body language is central to ensuring the quality of tutor-pupil and pupil-pupil interaction (Cooper, Brna, \& Martins, 2000). Acceptance and understanding of ideas and feelings, criticising, silence, questioning, all involve nonverbal elements of interaction (Knapp \& Hall, 2007). According to Cooper et al (2000), emotions can motivate and encourage; they can help people achieve goals.

Being aware of the process of learning can be a great help in helping others learn. The whole concept of learning, especially online, is shifting away from the provision of information to raising awareness of learning processes and helping others master these processes for themselves (Jacko, 2007).

\section{Method}

\subsection{The research objective and aims}

The researcher examined how the adolescents used digital media. The basics of how adolescents react to and behave in cyberspace are explored. It offers an investigation into self-expression and identity in the virtual world, as well as the effect of this realm on their levels of socio-emotional expressiveness to their online personas. In this study, the researcher 
expected frequent adolescent users of the internet to be lower on emotional intelligence, extroversion and agreeableness, but at the same time expected to see that the internet is not inherently unhealthy.

\subsection{Pupil media and technology survey}

The researcher administered this survey to the pupils to gain a picture of their media use, behaviours, attitudes and interests. The Pupil Survey was tailored to Grade 9 secondary school pupils and took approximately 20 minutes to complete.

In school A, 28 Grade 9 pupils participated.

In school B, 31 Grade 9 pupils participated.

In school C, 26 Grade 9 Pupils participated.

Approval was obtained from the school principals and the governing bodies of the participating schools, and approval from the Gauteng Department of Education was sought to conduct the research. All the pupils and parents who were selected to participate in the study were invited in June 2011 to indicate their interest in participating in this study through an information sheet and consent form. A parent or guardian was also required to give consent before a pupil could take part in the study. When a pupil chose not to take part or did not have a parental consent form, any statement they made was not included in the data.

The Grade 9 classes that participated were selected by using convenience sampling as the principals of the schools prioritised specific classes in that level in an effort to redress potential dangers of misusing and abusing media technology. A convenience sample is a sample where the participants are selected, in part or on the whole, at the convenience of the researcher (Leedy \& Ormrod, 2005). The researcher makes no attempt, or only a limited attempt, to ensure that this sample is an accurate representation of some larger group or population (Leedy \& Ormrod, 2005). Still, convenience samples can provide the researcher with useful information. Convenience sampling was used in this pilot study because it allowed the researcher to obtain basic data and trends regarding adolescents' media use and digital media literacy education without the complications of using a randomised sample. The convenience sampling technique is also useful in documenting that a particular quality of a substance or phenomenon occurs within a given sample (Gravetter \& Forzano, 2008). Such studies are also very useful for detecting relationships among different phenomena (Leedy \& Ormrod, 2005). Furthermore, by surveying only one class in each school, the researcher imposed on the school as little as possible.

The survey helped the pupils to reflect on their own digital media behaviours, but the results can also be used by programme leaders to create awareness among parents. The researcher also used this survey for programme assessment to measure change in the pupils in the following areas: time spent with new media, new media behaviours and interests, and parental involvement.

Upon approval by the school principals, the appropriate document packages were distributed to the three schools. Teacher instructions for introducing and managing the survey in the classroom were provided. The teachers were requested to give the pupils all the help they needed to understand the questions, but to ensure complete confidentiality that is, not to look at the pupils' responses. At the end of the session the teachers put the completed questionnaires in a return envelope and sealed it in the pupils' presence. These envelopes were sent directly to the researcher, who conducted the analysis and wrote the report.

\section{Results}

Respective perceptions of the pupils' use of new media were captured and trends in thinking identified in order to present a coherent picture.

\subsection{Pupils' digital landscape}

The Pupil Survey revealed that $79 \%$ of the pupils had internet access. Only $20 \%$ did not. More than $85 \%$ reported that they had accessed the internet during the previous month (August 2011). The vast majority $(73,2 \%)$ indicated that they had accessed the internet via their cellphones.

\subsection{Protecting online privacy}

The protection of online privacy is an issue of serious concern. To sign up for a free email account, $40 \%$ of the pupils 
would supply their real name and address, $37 \%$ only an email address, and only $19 \%$ would hesitate to supply any information. To register on a game site, $15 \%$ would give their real name and address, $55 \%$ only an email address, and $30 \%$ would supply no information. To create a profile on a dating site, $9 \%$ would give their real name and address, $16 \%$ only an email address, and $73 \%$ would give no information.

Six topics were set out in the survey and the pupils were asked if they would like to learn more about them in school. Protecting one's online privacy (72\%) was the leading topic, which is interesting as the pupils indicated that they often gave out personal information. Learning how to tell if information you find on the internet is true (68\%) followed closely. All the other topics were of at least moderate interest: finding information: 47\%; internet technology: 40\%; legal issues: $39 \%$, and social issues: (33\%). The questionnaire listed hate sites, racism and cyberbullying as examples of social issues. Examples of legal issues were downloading, file sharing, copyright and plagiarism.

\subsection{What pupils like to do online}

In addition to using the internet to obtain information for school assignments, playing interactive games, and interpersonal communication seem to be important reasons. The survey revealed that the internet was used to access social networking sites as well as MXit, WhatsApp and BBM Instant Messengers to make new friends, to join chat groups, to interact with existing friends, and to exchange private messages, which the literature indicated as activities that are part of the social development of secondary school pupils or adolescents.

\subsection{Favourite sites}

The pupils were asked to list their three favourite internet sites. There are differences as well as many similarities between the pupils in different schools' responses. While groups differ in their choice of specific sites, the type of site is often similar. Overall, the choices of all the pupils are very similar.

Girls and boys have many top favourite sites in common. Game sites such as Addicting Games, Neopets and Runescape appear on both's favourites lists. In writing their choices, the respondents used various spellings for the same site, for example 'NeoPets', 'neopet', and 'Npets'. The various renditions were recoded into a single spelling in order for the results to be analysed. The girls tended to list social contact and music sites that do not appear on the boys' lists, while the boys listed more sports and game sites.

\subsection{Popular activities}

The survey revealed that the most popular activities on the internet were accessing information (68,7\%), downloading content $(50,2 \%)$ and obtaining information for school assignments $(39,8 \%)$. Using the internet to communicate was also very popular - in the form of chatting (20,4\%), receiving and sending emails (30\%), via Facebook $(32,5 \%)$ and instant messaging $(16,8 \%)$.

\subsection{Social interaction}

The survey revealed that Facebook remained the most popular web-based social networking site. Thirty-two per cent (32\%) of the pupils used Facebook for a number of activities. They tended to treat their profiles as private places where they could post detailed personal information. For example, close to half $(42,2 \%)$ posted a profile photo, and four in ten provided the names of their schools, photos of their friends and family, or their email addresses.

Besides sharing personal photos via social networking sites, $39,6 \%$ of the pupils confirmed that they had met a 'cyberfriend' with whom they communicated regularly. Close to half $(42,2 \%)$ confirmed that they had been approached by somebody for 'something upsetting' in the past.

These scores indicated that the internet as a meeting place was becoming more important, and it is hardly surprising that adolescents are interested in meeting some of their new acquaintances in person. A striking feature of the survey results was that a large majority of the pupils (75\%) had never met an online acquaintance in the real world. Of those how had, $27 \%$ described it as a bad experience, and $73 \%$ as a good one.

\subsection{Online identities}

The pupils used the internet to experiment with their identities. Sixty-one per cent (61\%) reported that they pretended to 
be someone else online. The questionnaire suggested five possible reasons for this, of which the following three were chosen by the pupils who had ever pretended to be someone else online: $20 \%$ said they did it because they wanted to see what it would be like to be older; $33 \%$ wanted to flirt with other people, and $23 \%$ wanted to have an appearance different from their real one.

These scores point out that the internet offers adolescents an environment where they feel anonymous and invisible. Although the pupils knew that everyone created alternate personae online, the survey revealed that they were often surprised when they discovered, sometimes by meeting someone offline, that that person had lied to them. Interestingly, they somehow expected that person to be exactly who they said they were. This even though they have very likely presented themselves differently to what they are in the physical world.

\subsection{The internet for school assignments}

The respondents were asked whether they would prefer to get information for school assignments from books in a library or from the internet. The internet was the clear winner: $59 \%$ favoured the online option, while $41 \%$ indicated books. One third (31\%) reported they used the internet once or twice per week for school assignments, while $18 \%$ reported that they almost never used the internet for this purpose.

\subsection{Self-rating of skills}

The pupils rated their skills levels in the general areas of their lives. Most of the skills listed in the questionnaire relate to the world of school and friends; only three are specifically electronic-based: skills for using the internet, skills for playing computer games, and skills for using cellphone technology. Skills for using cellphone technology (68\%) was by a slight margin the top ranked, followed by skills for using the internet (65\%) and playing computer games (6\%). The pupils as a group tended to be quite confident about their abilities. Both boys and girls felt confident about their internet and cellphone abilities.

Pupils who saw themselves skilled in making friends, telling jokes or making people laugh, and playing computer games reported spending three to four hours per day using a cellphone to communicate (talking or SMSing) or using the internet for entertainment and/or socialising. On the other hand, those who saw themselves skilled in mathematics, science, reading and the arts spent less time online and reported zero to one hour per day. What these scores indicate is that, for today's adolescents, making friends and being funny are skills that are rooted in electronic communication.

The composite scores suggest that the internet is an extension of everyday social life and an integral part of the associated skills. The majority of pupils did indeed report that the internet was a place for making new friends.

\subsection{Offensive sites}

The pupils were asked about their encounters with different types of offensive sites (porn, violence or gore, gambling and hate sites, and adult chat rooms). In that school year (2011), more than three in ten (34\%) pupils had visited one or more of these sites intentionally, 35\% did it by accident, and 31\% did not at all. What is noteworthy is that more than twice as many boys as girls had visited these sites intentionally - $41 \%$ of the boys compared to only $18 \%$ of the girls. Socioeconomic class also played a role: More pupils from schools (middle to upper socio-economic class) than pupils from schools (lower socio-economic class) had visited one or more of these sites intentionally. Porn sites were most frequently visited (22\%), followed by violence or gore sites (20\%) and adult chat rooms (16\%). Interestingly, fewer pupils from the middle to upper socio-economic class schools, and specifically fewer boys, saw the need for protection from offensive internet sites compared to those from the lower socio-economic class school. These results indicate that adolescents who visit offensive sites intentionally do not see the same need for protection as adolescents who do not visit these sites intentionally.

\subsection{Bullying and sexual harassment}

Several questions concerning bullying and sexual harassment were asked Thirty-eight per cent (38\%) of the pupils reported that they had been bullied in the relevant school year (2011), and 17\% that they had been sexually harassed. Among those who reported bullying, via the internet was the most common way it occurred. Sixty-two per cent (62\%) reported being cyberbullied, and $22 \%$ indicated that they had been bullied at school. As far as sexual harassment is concerned, the situation was reversed: $43 \%$ reported being sexually harassed at school or home, and $12 \%$ reported 
being sexually harassed via the internet.

The survey also revealed a link between bullying and sexual harassment. Of the pupils who had been bullied, $18 \%$ also reported being sexually harassed. Only $4 \%$ of the pupils who had not been bullied reported being sexually harassed. Those who reported sexual harassment via the internet were asked about the person who had harassed them. More than half said it was someone they knew in the real world. Only $1 \%$ said it was a person older than them.

There is a marked difference between the number of pupils from middle to upper socio-economic class and those from the lower socio-economic class schools who reported bullying. Exactly twice as many pupils (56\%) from middle to upper socio-economic class schools as those from the lower socio-economic class school (28\%) reported being bullied. This either implies that the incidence of bullying is much lower in lower socio-economic class than in middle to upper socio-economic class schools, or that there is a cultural difference in the way bullying is defined. Such a difference might be attributed to the way in which the school management and parents of the different schools treat the issue.

\subsection{Rules in the home}

The majority of pupils reported that there were rules in their households about specific internet activities. The three most common rules, in $69 \%$ of the households, pertained to:

- the amount of time spent on the internet;

- $\quad$ sites that were off limits, and

- supplying personal information online.

The existence of rules suggests adult supervision. Eighty-two per cent (82\%) of the pupils reported that an adult was never present when they used the internet, and $20 \%$ reported that they were never supervised. In homes with internet access, it was common for the computer to be in a bedroom or private area of the home.

When asked whether they had discussed certain topics with their parents during the relevant school year, the majority (58\%) of the pupils stated that they had never discussed any of the topics listed in question 35 of the questionnaire.

The fact that internet use, an activity that accounts for a large proportion of adolescents' time, is largely absent from family conversation is worrying. The researcher sought to establish whether rules made a difference to adolescents' online behaviour, and the survey revealed that the existence of rules did indeed make a big difference. While the survey questions concerned specifically rules, school managements should treat the issue in terms of greater parental interest and involvement in the area of digital media literacy.

\subsection{Time spent with new media versus time spent on other activities}

Are the three or more hours per day the pupils reported spending with their cellphones a lot or a little?

The researcher wishes to emphasise that the answer to this question raises a red flag against too easily concluding that time spent with new media is synonymous with time taken from other activities. When answering this question, it is also important to keep in mind that many activities are not independent. That is, just as adolescents often engage in several media activities simultaneously, they, too, often engage in multiple activities of which some are not media-related. For example, adolescents often spend time with their parents and watch TV at the same time; they exercise while listening to music or hanging out with friends, and they quite typically do homework with music in the background, and often while simultaneously talking on the cellphone.

Whether or not one has relatively objective reference points with which to compare judgements of whether adolescents spend too much or too little time with various new media, one's judgement depends on subjective, evaluative views of the medium and the comparison standard. Therefore, one's judgement about whether three hours of cellphone use per day is a good, bad or neutral thing will depend on whether cellphone use is compared with the one hour they devote to homework on a typical day. In short, evaluations of whether the time spent with any of the activities mentioned in the survey is too much or too little, good or bad, depend on who is making the judgement and how they specific feel about each of the activities.

\section{Discussion}

This study has revealed aspects of new media use that are perceived to be problematic as they could negatively impact on adolescents' psychological well-being. Secondary school pupils have not yet developed the judgement to always make great decisions, but they are smart enough to understand the effects of risky practices. 
This research has identified a need to find ways to define overuse, and to differentiate between internet addiction and obsession, self-medicating for depression and other disorders and compulsions.

It is possible that an adolescent pupil could have a pathological relationship with a specific aspect of the internet, such as viewing pornography or online gaming, but that does not make the internet itself addictive. For example, whether viewing pornography on a computer or face-to-face does not affect whether or not it is pathological. An adolescent with poor impulse control can lose sleep over a suspenseful novel or favourite television show or a computer game or the temptation to click on another web link. Further investigation into many psychosocial factors is needed in order to ascertain just how overuse of the internet and digital media impact on adolescents' lives. However, this study maintains that adolescent pupils who are addicted to surfing the web are more likely to engage in aggressive behaviour. Suler (2007) also found it everything but uncommon for people to get aggressive in this realm. Due to the online disinhibition effect, people argue, criticise, berate and insult others without much provocation (Suler, 2007). This might be the collecting ground for the argument that cyberspace does make adolescents more aggressive. Vieru (2009) points out that it could be that using the internet causes adolescents to behave more aggressively, or that aggressive adolescents seek out the internet.

\section{Limitations of the Study}

In the South African context, there is not a plethora of research findings or guidelines for adolescent pupils' exposure to new media. The implementation of digital media literacy education that improves critical thinking increases benefits and reduces risks associated with such new media. There is not much local tangible research when compared to the numerous studies that have been undertaken on an international scale. Worldwide, research about adolescent pupils who are greatly exposed to new media and the associated psychosocial risks, including perpetrating and being a victim of cyberbullying, goes back at least 20 years, providing a valuable basis of findings and methods for dealing with these problems and the evaluation of quality media literacy education programmes integrated into a school curriculum. It is hoped that this study will in some way contribute to limited local research, and also inform what needs to go into a quality digital media literacy intervention programme for secondary schools in South Africa.

During the course of the investigation, certain limitations became apparent, some of which are the following:

- The experimental group consisted of pupils from three secondary schools from Gauteng Province only. The results may differ when adolescent pupils from other provinces are placed in the equation.

- Although the questionnaire respondents were very clearly asked to answer each question as honestly as possible, there may have been those pupils who were not entirely truthful.

- The findings cannot be generalised to all Grade 9 pupils in secondary schools. Tendencies can merely be indicated as the investigation may have revealed tendencies that are applicable to a specific category school. Qualitative research is, by its nature, exploratory. It is designed to gain an understanding of the range of opinions held about the topic area, not to determine the weight of those opinions among the general population. The results of the research of this type may therefore be viewed as indicative, not projectable.

\section{Recommendations}

As the internet is becoming a vital part of school activities the researcher suggests that several strategies across all school levels be implemented to prevent pupils from becoming addicted to the internet, as well as from abusing it, for instance in the form of cyberbullying:

- Educate school administrators and teachers on the dynamics of internet abuse in order to raise awareness and prevention throughout the school system.

- Implement educational programmes with specific reference to Emotional Intelligence that address pupil addiction that are similar to alcohol awareness and prevention programmes for adolescents. Life skills programmes that educate pupils on the warning signs and risk factors of internet addiction can promote early detection and reduce incidence.

- Encourage pupils to seek counselling when internet-triggered problems arise.

- Emphasise the importance of pupils' participation in the social activities that the school offers. Encourage pupils to get offline and join sport activities.

- Bring in professional experts in this field as school speakers to discuss cyberbehaviour to help expand pupils' understanding of the implications of new media. 
- Most school counsellors know little, if anything, about the ways of the internet, or its special allure for pupils. In order to aid the pupils, it is crucial that they learn everything about the internet and what pupils do there. They have to be able to talk to pupils about their online activities and ask them questions about what they get out of it. They have to go online themselves and see what goes on in chat rooms, and what interactive online games look like. And when a pupil reports depression or anxiety, they have to inquire about the pupil's internet habits.

- Emotional Intelligence development should form part of every subject's curriculum.

- Digital media literacy education must be a grassroots movement - teachers need to take the initiative in lobbying for its inclusion in the Life Orientation curriculum.

\section{Conclusion}

It is, however, also true that the internet is largely a prosocial interactive and information-driven medium. This study claims that the internet has tremendous potential to affect the emotions of adolescents, and in turn alter their selfperception and anxiety levels.

The resulting issues have created an urgent need for research with cyberbalance as its aim. It is essential that today's adolescents are taught from an early age the benefits and cautions associated with new media use, as well as how to use it responsibly. Adolescents need to find ways of using these media more positively in their lives, or they may end up being victims or perpetrators of cyberbullying, the consequences of which can be most damaging.

Adolescents' fantasies are given free rein, and the idea of being with their online friends can exceed all realistic expectations. Since few real-life relationships can compete with these wild, fantasy relationships, internet addicts will prefer to spend more and more time with their online friends.

This study also suggests that one of the major reasons why adolescents misuse new media, and the internet is so addicting, is the lack of limits and the lack of emotional intelligence and critical-thinking skills. Corrective strategies include digital media literacy education, content control, accountability and parental guidance. Above all, today's adolescent pupils are in need of a digital media literacy education with specific reference to Emotional Intelligence that equips them with four crucial life skills: critical thinking, responsibility, an appreciation of differences, and efficacy.

\section{References}

Bartneck, C. 2001. How Convincing is Mr. Data's Smile: affective expressions of machines. User Modeling and User-Adapted Interaction 11:279-295.

Birnbaum, M. 2000. Psychological experiments on the Internet. Retrieved from http://psych.fullerton.edu/mbirnbaum/web/lntroWeb.htm (accessed 28 January 28 2011)

Bradberry, T., \& Greaves, J. 2009. Emotional Intelligence 2.0. SanDiego: TalentSmart.

Carberry, S., \& De Rosis, F. 2008. Introduction to special Issue on 'Affective modeling and adaptation'. Journal User Modeling and UserAdapted Interaction 18(2):1-9.

Carroll, R. J. 2003. Variances are not always nuisance parameters. Biometrics 59(2):211-200.

Cooper, B., Brna, P., \& Martins, A. 2000. Effective Affective in Intelligent Systems - Building on Evidence of Empathy in Teaching and Learning. In A. Paiva (Ed.), Affective Interactions: Towards a New Generation of Computer Interfaces, 21-34. London: Springer Verlag.

Correa, T., Hinsley, A. W., \& De Zuniga, H. D. 2010. Who interacts on the Web? The intersection of users' personality and social media use. Computers in Human Behavior 26(2):247-253.

Creed, C., \& Beale, R. 2006. Multiple and extended interactions with affective embodied agents. In C. Peter, R. Beale, E. Crane, L. Axelrod \& G. Blyth (Eds.), Emotion in HCl: Joint proceedings of the 2005, 2006 and 2007 Intl. Workshops, 123-136. Stuttgart: Fraunhofer IRB Verlag.

Ekman, P. 1999. Basic Emotions. In T. Dalgleish \& M.J. Power (Eds.), Handbook of Cognition and Emotion, 43-60. Chishester: John Wiley \& Sons.

Engelberg, E., \& Sjöberg, L. 2004. Internet use, social skills, and adjustment. CyberPsychology \& Behavior 7:41-47

Etcoff, N. L., \& Magee, J. J. 1992. Categorical perception of facial expressions. Cognition 44: 227-240.

Givens, D. B. 2002. The Nonverbal Dictionary of Gestures, Signs, and Body Language Cues. Washington, DC: Center for Nonverbal Studies Press.

Goleman, D. 1996. Emotional Intelligence: Why it can matter more than IQ. London, UK: Bloomsbury Publishing.

Goleman, D. 2004. Emotional Intelligence: Why it can matter more than IQ \& Working with Emotional Intelligence. London, UK: Bloomsbury Publishing.

Gorman, L., \& McLean, D. 2009. Media and society into the 21st century: a historical introduction (2nd ed.). Chichester, UK: WileyBlackwell.

Gratch, J., \& Marsella, S. C. 2005b. Lessons from Emotion Psychology for the Design of Lifelike Characters. Applied Artificial 
Intelligence 19(3-4):215-233.

Gravetter, F. J., \& Forzano, L. B. 2008. Research methods for the behavioral sciences (4th ed.). Belmont: Wadsworth.

Gross, E. F., Juvonen, J., \& Gable, S. L. 2002. 'Internet Use and Well-Being in Adolescence'. Journal of Social Issues 58(1):75-90.

Hamburger, Y. A., \& Ben-Artzi, E. 2000. The relationship between extraversion and neuroticism and the different users of the Internet. Computers in Human Behavior 16:441-449.

HayGroup. 2011. Emotional Intelligence programs and services. Retrieved from http://www.google.com/Top/Science/Social_Sciences/ Psychology/Intelligence/ Emotional_Intelligence/ (accessed 18 February 2011)

Jacko, J. A. (Ed.). 2007. Human-Computer Interaction. HCl Intelligent Multimodal Interaction Environments. Conference Proceedings of the 12th International Conference, $\mathrm{HCl}$. New York: Springer.

Kirsh, L., \& Becker, J. 2006. 'Sexual Offending: Theory of Problem, Theory of Change, and Implications for Treatment Effectiveness'. Aggression and Violent Behavior 11:208-24.

Knapp, M. L., \& Hall, J. A. 2007. Nonverbal Communication in Human Interaction (5th ed.). Wadsworth: Thomas Learning.

Kraut, R. E., Patterson, M., Lundmark, V., Kiesler, S., Mukhopadhyay, T., \& Scherlis, W. 1998. Internet paradox: A social technology that reduces social involvement and psychological well-being? American Psychologist 53(9):1017-1032.

Kraut, R., Kiesler, S., Boneva, B., Cummings, J., Helgeson, V., \& Crawford, A. 2002. Internet Paradox. Journal of Social Issues 58(1):4974.

Leedy, P. D., \& Ormrod, J. E. 2005. Practical Research: Planning and Design. New Jersy: Merill Prentice Hall.

Lewis, M. M. 2003. Next: The Future Just Happen. New York: Norton Publishers.

Mayer, J. D., Caruso, D. R., \& Salovey, P. 2000. Emotional Intelligence Meets Traditional Standards for an Intelligence. Intelligence 27(4):267-298.

McKenna, K. Y. A., \& Bargh, J. A. 2000. Plan 9 from cyberspace: The implications of the Internet for personality and social psychology. Personality and Social Psychology Review 4(1):57-75.

Mueller, J. (2000). Review Essay: The Psychology of the Internet by Patricia M. Wallace. International Electronic Journal for Leadership in Learning 4(3). Retrieved from http://www.ucalgary.ca/iejll/vol4 (accessed 18 February 2011)

Orlik, P. B., Anderson, S. D., Day, L. A., \& Patrick, L. 2007._Exploring Electronic Media: Chronicles and Challenges. Malden, MA: WileyBlackwell.

Salovey, P., \& Mayer, J. D. 1990. Emotional Intelligence. Imagination, Cognition and Personality, 9:185-211.

Segal, J. 2008. The Language of Emotional Intelligence: The Five key skills for building powerful and effective relationships. New York: McGraw Hill.

Singh, G. 2010. High internet use is related to low emotional intelligence. Retrieved from http://www.examiner.com/cognitive-science-innational/high-internet-use-is-related-to-low-emotional-intelligen ce?render=print (accessed 15 April 2011).

Staples, B. 2004. What Adolescents Miss When We Let Them Grow Up in Cyberspace. The New York Times 29 May. Retrieved from http://www.nytimes.com/2004/05/29/opinion/29SAT4.html?th=\&page (accessed 12 November 2010)

Suler, J. 2007. Psychology of cyberspace. Retrieved from http://users.rider.edu/ suler/ suler/psycyber/ (accessed 12 February 2011)

Tarpley, T. 2001. Children, the Internet, and Other New Technologies. In D. G. Singer \& J. L. Singer (Eds.), Handbook of Children and the Media, 547-556. CA: Sage.

Tobin, R. M., Graziano, W. G., Vanman, E., \& Tassinary, L. 2000. Personality, emotional experience, and efforts to control emotions. Journal of Personality \& Social Psychology 79:656-669.

Trappl, R., Petta, P., \& Payr, S. (Eds.). 2003. Emotions in Humans and Artifacts. Cambridge: MIT Press.

Vieru, T. 2009. Internet addiction makes teens more aggressive. Retrieved from http://news.softpedia.com/news/Internet-AddictionMakes-Teens-More-Aggressive-105261.shtml (accessed 13 February 2011).

Von Dras, D. D., \& Siegler, I. C. 1997. Stability in extraversion and aspects of social support at midlife. Journal of Personality \& Social Psychology 72:233-241.

Wang, H., Predinger, H., \& Igarashi, T. 2004. Communicating Emotions in Online Chat Using Physiological Sensors and Animated Text. Conference Proceedings of the ACM CHI Conference 24-29 April, Vienna, Austria, New York: ACM Press. 